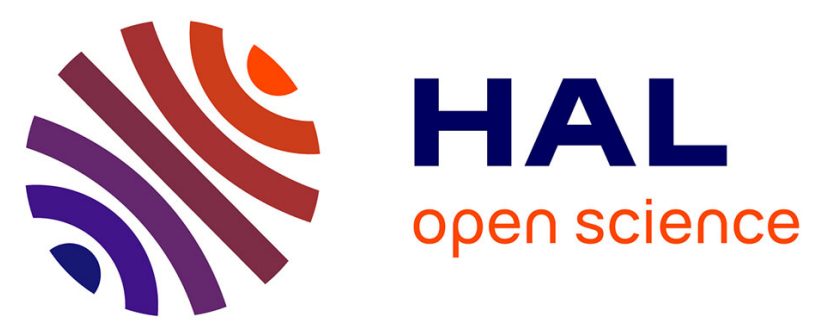

\title{
Investigating the relationship between the mechanical properties of plasma polymer-like thin films and their glass transition temperature
}

Nathan Vinx, Pascal Damman, Philippe Leclère, Bruno Bresson, Christian Fretigny, Claude Poleunis, Arnaud Delcorte, Damien Cossement, Rony Snyders, Damien Thiry

\section{To cite this version:}

Nathan Vinx, Pascal Damman, Philippe Leclère, Bruno Bresson, Christian Fretigny, et al.. Investigating the relationship between the mechanical properties of plasma polymer-like thin films and their glass transition temperature. Soft Matter, 2021, 10.1039/D1SM01134K . hal-03414733

HAL Id: hal-03414733

https://hal-espci.archives-ouvertes.fr/hal-03414733

Submitted on 4 Nov 2021

HAL is a multi-disciplinary open access archive for the deposit and dissemination of scientific research documents, whether they are published or not. The documents may come from teaching and research institutions in France or abroad, or from public or private research centers.
L'archive ouverte pluridisciplinaire HAL, est destinée au dépôt et à la diffusion de documents scientifiques de niveau recherche, publiés ou non, émanant des établissements d'enseignement et de recherche français ou étrangers, des laboratoires publics ou privés. 


\section{Investigating the relationship between the}

\section{mechanical properties of plasma polymer-like thin}

\section{films and their glass transition temperature}

Nathan Vinx, ${ }^{1}$ Pascal Damman, ${ }^{2}$ Philippe Leclère, ${ }^{3}$ Bruno Bresson, ${ }^{4}$ Christian Fretigny, ${ }^{4}$ Claude Poleunis, ${ }^{5}$ Arnaud Delcorte, ${ }^{5}$ Damien Cossement, ${ }^{6}$ Rony Snyders ${ }^{1,6}$, and Damien Thiry ${ }^{1 *}$

${ }^{1}$ Chimie des Interactions Plasma-Surface (ChIPS), CIRMAP, University of Mons, 20 Place du Parc, B-7000 Mons, Belgium

${ }^{2}$ Interface et Fluides Complexes (Influx), CIRMAP, University of Mons, 20 Place du Parc, B7000 Mons, Belgium

${ }^{3}$ Laboratory for Chemistry of Novel Materials (CMN), CIRMAP, University of Mons, 20 Place du Parc, B-7000 Mons, Belgium

${ }^{4}$ Sciences et Ingénierie de la Matière Molle (SIMM), ESPCI, 10 rue Vauquelin, F-75231 Paris Cedex 05, France

${ }^{5}$ Institute of Condensed Matter and Nanosciences (IMCN), Université catholique de Louvain (UCL), Place Louis Pasteur 1, B-1348 Louvain-la-Neuve, Belgium

${ }^{6}$ Materia Nova Research Center, Parc Initialis, B-7000 Mons, Belgium 


\section{$\underline{\text { Abstract }}$}

This work aims at understanding the influence of the substrate temperature $\left(\mathrm{T}_{\mathrm{s}}\right)$ on the viscoelastic properties of propanethiol plasma polymer films (PPF). By means of state-of-the-art AFM characterization-based techniques including Peak Force Quantitative Nanomechanical Mapping (PFQNM), nano Dynamic Mechanical Analysis (nDMA) and "scratch" experiments, it has been demonstrated that the PPF mechanical behaviour is dramatically affected by the thermal conditions of the substrate. Indeed, the material behaves from a high viscous liquid (i.e. viscosity $\sim 10^{6}$ Pa.s) to a viscoelastic solid (loss modulus $\sim 1.17 \mathrm{GPa}$, storage modulus $\sim 1.61 \mathrm{GPa}$ ) and finally to an elastic solid (loss modulus $\sim 1.95 \mathrm{GPa}$, storage modulus $\sim 8.51 \mathrm{GPa}$ ) when increasing $\mathrm{T}_{\mathrm{s}}$ from 10 to $45^{\circ} \mathrm{C}$. This behaviour is ascribed to an increase in the surface glass transition temperature of the polymeric network. The latter has been correlated with the chemical composition through the presence of unbounded molecules acting as plasticizers and the crosslinking density of the layers. In a second step, this knowledge is exploited for the fabrication of nanopattern by generating surface instabilities in propanethiol PPF/Al bilayer system. 


\section{Introduction}

Thin polymer films $(<1 \mu \mathrm{m}$ thick) are increasingly gaining in interest for their attractive properties including their light weight, their easiness of processing, their low manufacture cost, and their wide range of physicochemical properties. Such materials can be employed in various fields of applications such as the corrosion protection, ${ }^{1,2}$ as biomedical materials (e.g. antibacterial coatings, ${ }^{3,4}$ cell culture substrates ${ }^{5,6}$ ) or in the electronics industry (e.g. light-emitting devices, ${ }^{7,8}$ organic solar cells, ${ }^{9}, 10$ ). Among other physicochemical features (e.g. chemical composition, surface topography), adapted mechanical properties of the polymer films are a crucial requirement to use these materials in many of these applications. For instance, it has been demonstrated that the mechanical properties of polymer films strongly affect the sensitivity of flexible pressure sensors or the proliferation and differentiation of cells when used as cells culture substrates. ${ }^{11,12}$ Furthermore, the ability to tune the mechanical properties of polymer films is also the basis of recent attractive strategies (e.g. nanoimprint lithography, wrinkling) $)^{13-15}$ for controlling the morphology of organic/inorganic material at the micro/nano scale which enlarge the field of applications of these materials towards flexible electronic, sensors or anti-fouling coatings. ${ }^{16-21}$ Therefore, controlling the mechanical properties of polymers films turns out to be a necessity. ${ }^{22}$

Among the plethora of techniques employed for the deposition of polymer thin films (e.g. spin casting, spin coating, initiated chemical vapor deposition, etc.), the plasma polymerization appears as one of the most promising. Indeed, the inherent substrate-independent nature of the process, the low environmental impact of the technique, the outstanding properties of the grown layers (i.e., high thermal stability, insolubility in most of solvents) and an exquisite control of their physicochemical properties by adjusting the process parameters justify the popularity gained by this process. ${ }^{23}$ Briefly, the growth mechanism of the layers is based on the activation of an organic 
vapor in a plasma resulting in the formation of reactive species (i.e. ions and mainly radicals) which further condensate at the substrate surface giving rise to the formation of an organic thin film referred as plasma polymer films (PPF). ${ }^{24}$ This complex growth mechanism including a multitude of gas phase and surface reactions pathways is responsible for the unconventional character of the PPF such as the absence of repeating units. ${ }^{25,26}$ To date, the emphasis mainly concerned the control of the chemical composition of PPF (i.e. the presence of specific chemical functionalities such as $-\mathrm{COOH},{ }^{27}-\mathrm{OH},{ }^{28}-\mathrm{NH}_{2}{ }^{29}$ or $-\mathrm{SH}^{30}$ and their corresponding densities) by adjusting the synthesis parameters. In contrast, the mechanical properties of functionalized PPF have received little attention. From the few studies dealing with the investigation of their mechanical properties, it can been learned that the rigidity modulus (i.e. Young modulus) of PPF rather exhibits a high value typically ranging from 0.5 to $10 \mathrm{GPa}$ depending on the synthesis conditions (i.e. mainly the energy input) and on the chemical precursor. ${ }^{31-33}$ Nevertheless, if interesting, this information is likely not enough to fully describe the viscoelastic behavior of the PPF. Finally, the concept of glass transition admitted to be directly correlated to the viscoelastic properties of polymers has never been employed, in the context of PPF materials, to discuss their mechanical properties. To the best of our knowledge, the characterization of the viscoelastic behavior of PPF remains to be carried out and the link with the physicochemical properties (i.e. chemical composition, cross-linking density) or the glass transition temperature of the coatings is still open to question.

In this context, the objective is to enlarge the understanding of the relationship between the mechanical properties of PPF and the growth conditions. Particularly, we aim at a better understanding of the link between the glass transition of PPF materials and their viscoelastic behavior. As a model system, propanethiol PPF prepared by varying the substrate temperature $\left(\mathrm{T}_{\mathrm{s}}\right)$ 
are investigated. This choice is motivated by our recent work revealing the wide control that offers $\mathrm{T}_{\mathrm{s}}$ on the deformation of propanethiol PPF when involved in bilayer systems with a top Al sputtered coating. ${ }^{34}$ For certain synthesis conditions, a spontaneous morphological reorganization supposed to be highly dependent on the mechanical properties of PPF takes place resulting in the formation of a wrinkled surface of interest for many applications such as the fabrication of flexible electrodes. Here, in this work, at first, a deep characterization of the viscoelastic mechanical properties (i.e. rigidity/loss/storage moduli, loss factor, ...) of the propanethiol PPF versus $\mathrm{T}_{\mathrm{s}}$ is carried out at the nanoscale by means of the Peak Force Quantitative Nanomechanical Mapping (Peak Force QNM), nano Dynamic Mechanical Analysis (nDMA) and scratching experiments by AFM. Then, these data are correlated with the determination of the glass transition temperature by ToF-SIMS measurements. To identify the main factors governing this transition, a thorough characterization of the physicochemical properties of the PPF including their chemical composition (from XPS) and cross-linking degree (from ToF-SIMS) is undertaken. Finally, taking benefit of the knowledge gained in the first part, the flexibility offered by our strategy to tune the mechanical properties of PPF is exploited to control the wrinkling phenomenon in bilayer systems. 


\section{$\underline{\text { Experimental }}$}

Substrate preparation. The propanethiol-based PPF have been deposited from 1-propanethiol (99\%, Sigma-Aldrich) on $1 \times 1 \mathrm{~cm}^{2}$ Silicon wafers. Before their introduction in the deposition chamber, the substrates have been washed with 1-isopropanol three times and dried under a nitrogen flow.

Plasma polymerization. The depositions have been carried out in a metallic vacuum chamber (65 $\mathrm{cm}$ in length, $35 \mathrm{~cm}$ in diameter) pumped by a combination of turbomolecular and primary pumps allowing to reach a residual pressure lower than $2.10^{-6}$ Torr. More details about the deposition chamber can be found elsewhere. ${ }^{35}$

During the process, the working pressure has been controlled using a throttle valve connected to a capacitive gauge to maintain it at 40 mTorr. The plasma has been sustained by a water-cooled copper coil located inside the chamber and connected to an Advanced Energy RF (13.56 MHz) power supply through a matching network. During the depositions, the substrates (at the floating potential) have been located at $10 \mathrm{~cm}$ from the copper coil. For all experiments, the precursor flow rate and the power applied to the coil have been fixed at $10 \mathrm{sccm}$ and $40 \mathrm{~W}$, respectively.

The substrate temperature has been measured during the depositions using a thermocouple affixed to the substrate holder. This parameter has been externally controlled through a combination of electrical resistances (heating) and liquid nitrogen (cooling) to keep it constant ( \pm $1^{\circ} \mathrm{C}$ ) during the experiments. For all experiments, the substrate temperature has been fixed 30 minutes before starting the deposition ensuring a thermal equilibrium between the substrate holder and the substrate surface. Three different substrate temperatures have been investigated in this work: $10^{\circ} \mathrm{C}\left(\mathrm{PPF}_{10^{\circ}} \mathrm{C}\right), 23^{\circ} \mathrm{C}\left(\mathrm{PPF}_{23^{\circ}} \mathrm{C}\right)$ and $45^{\circ} \mathrm{C}\left(\mathrm{PPF}_{45^{\circ}} \mathrm{C}\right)$. This choice is guided by our previous 
work investigating the wrinkling phenomenon taking place considering propanethiol PPF as a bottom layer. ${ }^{34}$

Aluminum deposition. For the fabrication of a micro/nano pattern, an aluminum layer has been deposited on propanethiol PPF by magnetron sputtering in a second chamber directly after the synthesis of the PPF. The thickness of the Al coating has been fixed at 50nm. The deposition has been carried out with an Aluminum target (5cm in diameter) in an Ar atmosphere (flow rate of 40 sccm), at a pressure of $7 \mathrm{mTorr}$ and a power applied to the target of $100 \mathrm{~W}$.

Deposition rate measurements. The deposition rates have been obtained by measuring the thickness of the layers. For these measurements, a step has been generated using a silicon mask on the substrate and the difference of height between coated and uncoated part has been measured by AFM.

\section{Mechanical characterization.}

- Peak-Force QNM and nDMA (FFV) measurements. The mechanical properties of the PPF have been evaluated through an AFM composed of a Bruker Icon Dimension instrument, equipped with a Nanoscope V controller, with both the Peak-Force Quantitative Nanomechanical Mapping (Peak Force $\mathrm{QNM}^{\circledR}$ ) method and the nano Dynamic Mechanical Analysis, embedded in the Fast Force Volume mode. ${ }^{36,37}$ The first technique consists in mapping the mechanical properties of a sample area by recording at each pixel composing the image of the probed surface a force-distance curve at high rate (e.g. $2 \mathrm{kHz}){ }^{38}$ From each of these force-distance curves, the rigidity modulus is extracted, ${ }^{39}$ allowing the mapping of the mechanical properties. The analysis conditions limit the contact time between the tip and the sample surface to a millisecond or less, which entailed to work in the approximation of a purely elastic sample with frequency- 
independent properties. However, most of the time polymers cannot be considered as pure elastic solids but as viscoelastic ones, a frequency dependance has so to be considered. This is the context in which the nano Dynamic Mechanical Analysis (nDMA) makes sense. In the frequency employed in conventional DMA (i.e. $0,1-100 \mathrm{~Hz}$ ), less than one millisecond is too short to probe the viscoelastic behavior of samples. To that purpose, AFM-nDMA executes a force modulation during a longer time (e.g. several hundreds of milliseconds) while the AFM tip is in continuous contact with the sample. This measurement can be embedded into the Fast Force-Volume (FFV) mode to image viscoelastic parameters at different locations on the PPF surface at a fixed frequency, 80 $\mathrm{Hz}$ in our analysis conditions. All the measurements have been carried out on samples directly after their synthesis, at room temperature, on ambient air. The cantilever used for this analysis is a pre-calibrated "RTESPA-300-30" tip from Bruker ${ }^{\circledR}$, with a tip-radius of $27 \mathrm{~nm}$ and a spring constant of $48.79 \mathrm{~N} / \mathrm{m}$. The cantilever spring constant was checked by the thermal tune method to be compared to the value indicated by the supplier. ${ }^{40}$ The deflection sensitivity was measured on sapphire and was found to be $(58.81 \pm 0.60) \mathrm{nm} / \mathrm{V}$. The rigidity modulus value as well as the viscoelastic parameters characterizing the PPF mechanical properties have been evaluated with the JKR theory, which is generally applied for describing viscoelastic samples such as polymers. ${ }^{39,41}$ To ensure that the substrate does not influence, the measurements, the thickness of the coatings is fixed at $250 \mathrm{~nm}$.

- "Scratch" measurement. The viscosity of PPF has been evaluated by means of a two-step AFM method on an AFM composed of a Bruker Icon microscope equipped with a Nanoscope V controller. The microscope was operated in contact mode, using 
commercially available silicon tips from BudgetSensors (contAl-G) with a resonance frequency of about $13 \mathrm{kHz}$ and a typical radius of curvature indicated by BudgetSensors to be lower than $10 \mathrm{~nm}$. The spring constant of the cantilever was evaluated to $0.35 \mathrm{~N} / \mathrm{m}$. After recording the surface topography of the sample, the tip of the AFM has been pressed on the sample, and then forced to sweep the surface several times following a unidirectional virtual line of $5 \mu \mathrm{m}$. The resulting perturbation ("scratch") has been imaged over time to characterize the relaxation dynamics of the PPF. The deflection set point during the analysis has been switched from $25 \mathrm{nN}$ to $15 \mathrm{nN}$ from the first step to the second, and the topography has been recorded in a contact mode at an angle of $90^{\circ}$ from the virtual unidirectional line, in order to enhance the measurement precision.

Cross-linking degree evaluation. The evolution of the PPF cross-linking degree with $T_{s}$ has been assessed by means of ToF-SIMS measurements. After their synthesis, the deposited films have been directly transferred to the instrument. Static ToF-SIMS data have been acquired in positive mode using a ToF-SIMS IV instrument supplied by ION TOF GmbH. A pulsed $\mathrm{Ar}^{+} 10$ $\mathrm{keV}$ ion beam at a current of $0.75 \mathrm{pA}$ rastered over a scan area of $300 \times 300 \mu \mathrm{m}^{2}$ on $125 \mathrm{~s}$. At least 8 spectra per synthesis condition have been recorded.

Surface transition temperature evaluation. The determination of the surface transition temperature $\left(\mathrm{T}_{\mathrm{T}}\right)$, strongly correlated to the glass transition temperature $\left(\mathrm{T}_{\mathrm{g}}\right)$, of PPF as a function of $\mathrm{T}_{\mathrm{s}}$ has been achieved through ToF-SIMS measurements. ${ }^{42-44}$ The films have been analyzed less than $24 \mathrm{~h}$ after their synthesis. Static ToF-SIMS data have been acquired in positive mode using a ToF-SIMS V instrument provided by ION TOF GmbH. It was used both as sputtering and analytical source. The instrument is equipped with an Ar gas cluster ion beam (Ar-GCIB) that was operated at $10 \mathrm{keV}$ during the analyses with a cluster distribution centered on $\mathrm{Ar}_{3000}{ }^{+}$. An $\mathrm{AC}$ target 
current of $0.037 \mathrm{pA}$ with a bunched pulse width around $70 \mathrm{~ns}$ was used on a raster of $128 \times 128$ data points over an area of $500 \times 500 \mu \mathrm{m}^{2}$. To ensure the charge compensation while analyzing, an electron flood gun $(E k=5 \mathrm{eV})$ was used. The sample temperature was controlled with a special sample holder called "Holder G" also supplied by ION TOF GmbH. This holder allowed us to maintain the sample temperature from $-120^{\circ} \mathrm{C}$ to $+120^{\circ} \mathrm{C}$ with an accuracy of $\pm 1{ }^{\circ} \mathrm{C}$. The temperature has been stabilized for $20 \mathrm{~min}$ before each analysis. In order to ensure the elimination of all the surface contaminations, a pre-sputtering of $2 \times 10^{13} \mathrm{Ar}_{3000}{ }^{+} / \mathrm{cm}^{2}$ over an area of $1000 \mathrm{x} 1000 \mu \mathrm{m}^{2}$ was conducted in DC mode prior to each analysis. As it has been reported that the substrate interface can influence the glass transition temperature of polymer thin films, the thickness of the PPF is also fixed at $250 \mathrm{~nm}$ for these experiments enabling to exclude any substrate effect. $^{45}$

XPS measurement. The sulfur/carbon ratio in the PPF has been recorded by X-ray photoelectron spectroscopy (XPS). These analyses have been performed using a PHI 5000 VersaProbe apparatus directly connected under vacuum to the deposition chamber. A monochromatized $\mathrm{Al} \mathrm{K \alpha}$ line $(1486.6 \mathrm{eV})$ has been used as a photon source and a take-off angle of $45^{\circ} \mathrm{C}$ normal to the surface has been employed for electrons detection and collection. 


\section{$\underline{\text { Results and discussion }}$}

Since it is accepted that the surface topography can influence the measurement of the rigidity modulus, we first imaged the PPF surface (Figure S1). ${ }^{38}$ For all the samples, the calculated RMS roughness is found to be $<0.3 \mathrm{~nm}$ in line with the values found in the literature, ${ }^{25}$ making our measurements topography-independent.

In order to investigate the influence of the substrate temperature on the mechanical properties of PPF, the samples have been analyzed with the AFM Peak-Force QNM method.
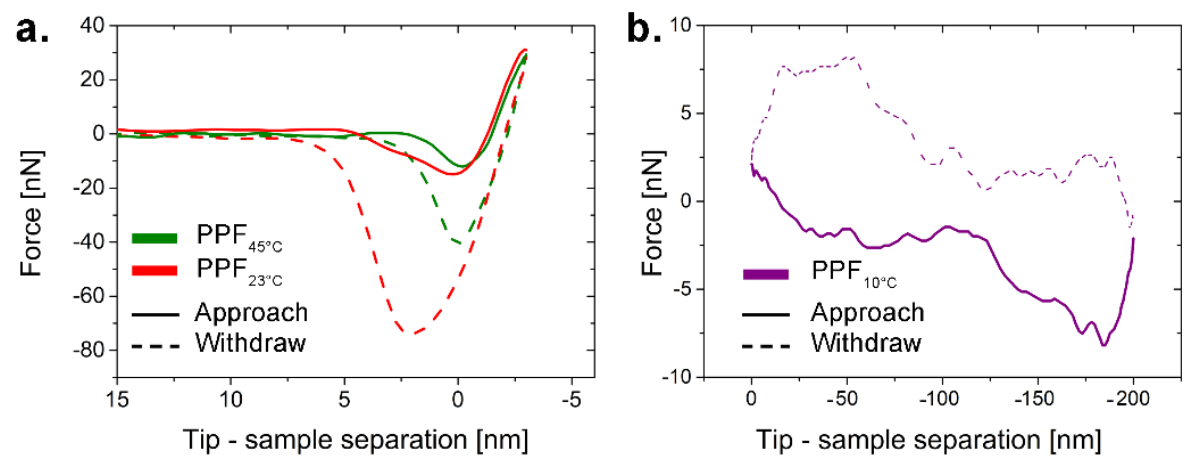

Figure 1: Typical force-distance curves recorded by AFM Peak Force measurements on (a)

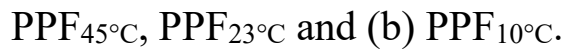

Typical approach-retract curves recorded for $\mathrm{PPF}_{23^{\circ} \mathrm{C}}$ and $\mathrm{PPF}_{45^{\circ} \mathrm{C}}$ are presented in Figure 1 a. If the curves have similar aspects, some differences can be observed in the PPF mechanical responses. For the peak force of $30 \mathrm{nN}$, the adhesion force, corresponding to the difference between the minimum and the baseline increases when the substrate temperature decreases from $45^{\circ} \mathrm{C}$ to $23^{\circ} \mathrm{C}$. Different viscoelastic properties or chemical composition of materials could explain this observation. This will be discussed later. From such curves, the rigidity modulus has been extracted by applying the JKR model. The analysis of these curves reveals that the rigidity modulus value increases from $5.10 \pm 0.49 \mathrm{GPa}$ to $9.94 \pm 5.88 \mathrm{GPa}$ when $\mathrm{T}_{\mathrm{s}}$ increases from 23 to $45^{\circ} \mathrm{C}$. These moduli are in line with the typical values generally reported in the literature for PPF. ${ }^{32}$ 
To deeper characterize the viscoelastic behavior of the PPF, nDMA experiments have been carried out at a frequency of $80 \mathrm{~Hz}$. To our knowledge, this recent technique developed by Brucker belongs to the few suitable techniques to investigate the viscoelastic properties of polymeric thin films such as plasma polymers. Indeed, the fine control over the loading force allows to limit the indentation to a few nanometers $(<1.5 \mathrm{~nm}$ in our experiments) allowing the analysis of $250 \mathrm{~nm}$ thick polymer films without the influence of the substrate on the measured parameters. The evolution of the storage modulus, the loss modulus and Tan Delta (i.e. phase angle), presented in

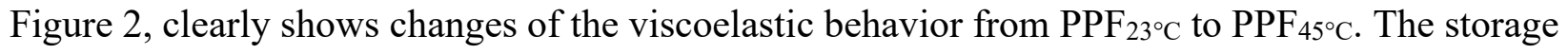
modulus increases from $1.61 \pm 0.28 \mathrm{GPa}$ to $8.51 \pm 3.54 \mathrm{GPa}$, in agreement with the rigidity modulus values measured from Peak-Force QNM. The loss modulus slightly evolves from 1.17 $\pm 0.22 \mathrm{GPa}$ to $1.95 \pm 1.11 \mathrm{GPa}$ when the substrate temperature increases. Consequently, the phase angle, which corresponds to the ratio between the loss and the storage moduli, decreases from $0.72 \pm 0.12$ to $0.24 \pm 0.09$ when $\mathrm{T}_{\mathrm{s}}$ increases. This behavior expresses a higher capacity of $\mathrm{PPF}_{23^{\circ} \mathrm{C}}$ compared to $\mathrm{PPF}_{45^{\circ} \mathrm{C}}$ to dissipate the mechanical energy into heat and a higher vibration damping ability. ${ }^{46}$

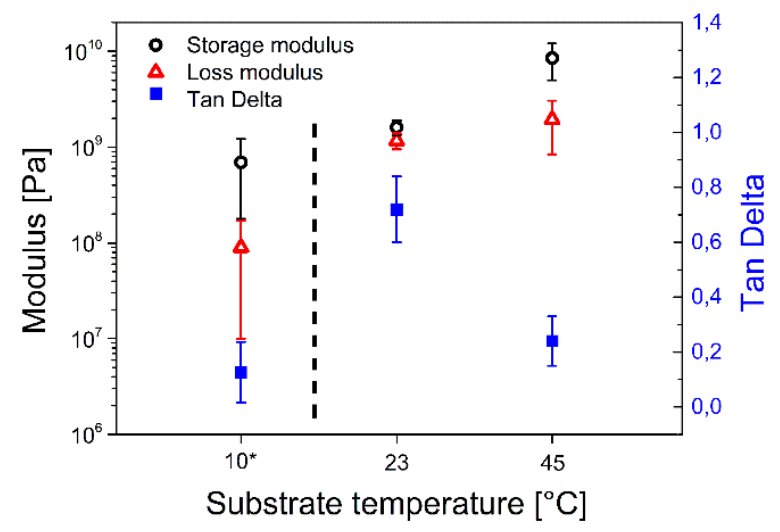

Figure 2: Evolution of the Tan Delta, storage and loss moduli of PPF as function of the substrate temperature. $10^{*}$ refers to a $\mathrm{PPF}_{10^{\circ}} \mathrm{C}$ annealed for $1 \mathrm{~h}$ at $150^{\circ} \mathrm{C}$ in air. 


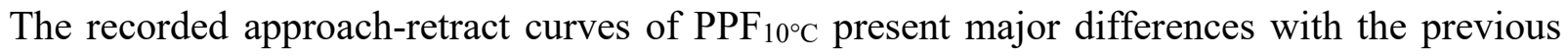
ones (Figure $1 \mathrm{~b}$ ). The tip penetrates the sample until reaching the solid substrate $(\sim 250 \mathrm{~nm})$ which suggests a much lower stiffness for this PPF. The shape of the curve makes impracticable any mathematical treatment for extracting mechanical parameters. Even the very nature of the layer, fluid or solid, is questionable.

Consequently, another method has been used for probing the mechanical behavior of this sample. In this case, the tip of the AFM has been used to sweep the surface along a distance of $5 \mu \mathrm{m}$, with a force of $25 \mathrm{nN}$. Consequently, two perturbations appear on the PPF surface, i.e. one scratch on the surface following the swept line and a bump, unambiguously indicating that motion of matter takes place (Figure 3 a). Such kind of surface deformations have already been observed in the literature for soft materials as for instance with soluble polyacetylene or PET polymers. ${ }^{47,48}$
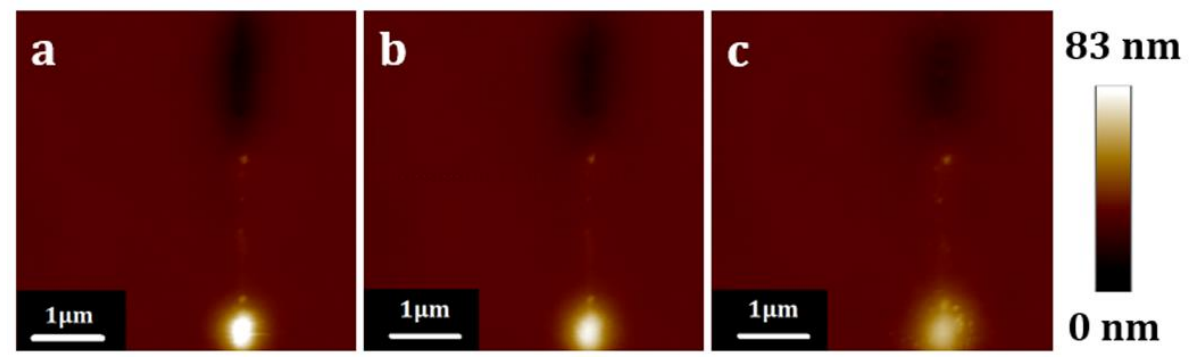

Figure 3: $2 \mathrm{D}$ AFM images of the $\mathrm{PPF}_{10^{\circ} \mathrm{C}}$ after the scratching perturbation: (a) $90 \mathrm{~s}$, (b) $327 \mathrm{~s}$ and (c) $2713 \mathrm{~s}$.

Following the scratching of the surface, it is observed that the PPF topography evolves as a function of time towards a recovery of the as-prepared surface without reaching this situation during the duration of the observation. This is depicted in Figure $3 \mathrm{~b}$ and c after $327 \mathrm{~s}$ and $2713 \mathrm{~s}$ respectively: the bump sinks while the hole refills. It is worth noting that the relaxation dynamics depends on the mechanical properties of the PPF. 
Considering the height of the perturbations (i.e. $\sim 18 \mathrm{~nm}$ for the scratch and $\sim 65 \mathrm{~nm}$ for the bump), the following discussion will only treat about the bump data offering a better resolution. It should however be noted that the following mathematical approach is suitable for both perturbations.
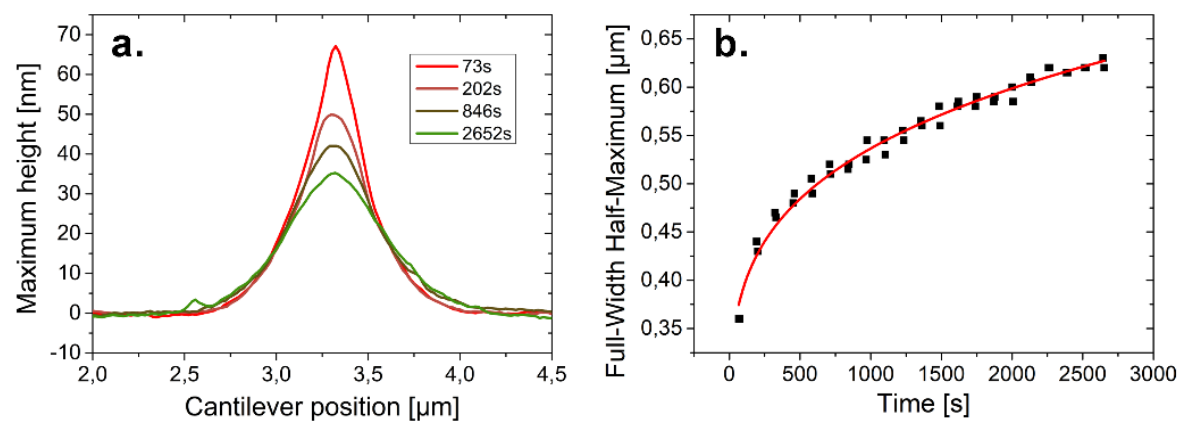

Figure 4: (a) Evolution over time of the bump profile generated on $P P F_{10^{\circ}} \mathrm{C}$. (b) Data (dots) and fitting curve (line) of the evolution over time of the full-width half-maximum of the bump profile on $\mathrm{PPF}_{10}{ }^{\circ} \mathrm{C}$

From the temporal evolution of the maximum-height profile for the bump, it can be observed that the amount of matter overhanging the PPF surface is indeed relaxing with time (Figure 4 a). The height of the bump decreases (by about 50\% after $45 \mathrm{~min}$ ) while the bump spreads on the PPF surface over time (i.e. from 1.4 to $1.85 \mu \mathrm{m}$ ) as shown in Figure $4 \mathrm{~b}$ depicting the evolution of the full-width half-maximum over time.

This set of data allows to access important information on the relaxation mechanisms and kinetics. A similar phenomenon has already been described in the literature by means of numerical simulations. In that case, the relaxation of PS droplet deposited on the same polymer above its glass transition temperature was studied ${ }^{49}$ This system describes the relaxation of a viscous thin film overhung by an amount of matter constituted of the same material, which conceptually can be compared to our situation. Based on these considerations, it appears that the $\mathrm{PPF}_{10}{ }^{\circ} \mathrm{C}$ behaves 
like a liquid. To validate this hypothesis, we have approached our results with this model describing the relaxation of a liquid thin film.

Assuming that the $\mathrm{PPF}_{10}{ }^{\circ} \mathrm{C}$ is a Newtonian liquid and its symmetry, the system can be described by a two-dimensional Stokes equation:

$\left(\frac{\partial P}{\partial x}\right)=\eta \frac{\partial^{2} v_{x}}{\partial z^{2}} \quad$ Equation 1

in which $\mathrm{x}$ is a direction included the plan of the PPF surface, $\mathrm{z}$ the perpendicular direction, $\mathrm{P}$ the pressure $\left[N \cdot \mathrm{m}^{-2}\right], \mathrm{v}_{\mathrm{x}}$ the velocity of the flow in the $\mathrm{x}$ direction $\left[\mathrm{m} \cdot \mathrm{s}^{-1}\right]$ and $\eta$ is the viscosity [N.s.m $\left.{ }^{-2}\right]$ of the PPF. Considering the PPF thickness $(\sim 250 \mathrm{~nm})$ which is low enough compared to the film area $\left(\sim 1 \mathrm{~cm}^{2}\right)$, the lubrication regime is here assumed..$^{50}$

The left-hand side term of Equation 1 represents the capillary forces while the right-hand side term corresponds to viscous forces. The capillary forces drive the shape relaxation, while the viscous forces slow down the flow of matter.

In the lubrication regime, the volume conservation of the film during the bump relaxation can be defined by:

$$
\left(\frac{\partial h}{\partial t}\right)=-\frac{\partial Q_{x}}{\partial x} \quad \text { with } \quad Q_{x}=h \bar{v}_{x} \quad \text { Equation } 2
$$

$\mathrm{Q}_{\mathrm{x}}$ is the PPF flux in the $\mathrm{x}$ direction and $\overline{\mathrm{v}}_{\mathrm{x}}$ the velocity in the $\mathrm{x}$ direction integrated over the velocity profile along $\mathrm{z}$. These equations describe the viscous flow, with a flow rate $\mathrm{Q}$ proportional to h.

By expressing the capillary forces as a function of the Young-Laplace equation, Equation 1 can be rewritten in order to explicit the average velocity in the $x$ direction integrated over time. ${ }^{51}$ Inserting this new expression in the Equation 2 gives:

$\frac{\partial h}{\partial t}=-\frac{\gamma}{\eta} \frac{\partial}{\partial x}\left[h^{3} \frac{\partial^{3} h}{\partial x^{3}}\right] \quad$ Equation 3 
Equation 3 describes the time evolution of the bump shape during the relaxation. As the height of the perturbation decreases, its width consequently increases. This equation can be expressed in scaling laws by expressing $\mathrm{h}$ as a constant. This assumption is justified considering that the matter flows through the whole film; $h$ can thus be expressed as a constant $h_{0}$. By posing $\mathrm{L}$ as the width of the perturbation in the $\mathrm{x}$ direction, the Equation 3 can be solved as:

$$
L \sim\left(\frac{\gamma}{\eta} h_{0}^{3}\right)^{1 / 4} t^{1 / 4} \quad \text { Equation } 4
$$

In this equation, $\mathrm{h}_{0}$ is the film thickness and $\mathrm{L}$ the bump width. According to this theoretical expression, the width of the perturbation is supposed to evolve with a time dependence following a power law with an exponent value of $1 / 4$. This power law adequately fits our experimental data regarding the evolution of the half-width maximum of the bump (Figure $4 \mathrm{~b}$ ). Consequently, these

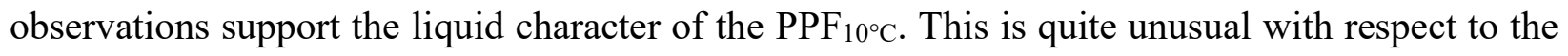
literature, where plasma polymers are generally described as hard and solid materials. ${ }^{31,32}$

The viscosity $\eta$ of this liquid PPF can be evaluated from the fitting data considering a surface tension value, $\gamma$, of $10^{-2} \mathrm{~N} / \mathrm{m}^{.52}$ The PPF thickness, $\mathrm{h}_{0}$, is $2.10^{-7} \mathrm{~m}$. The obtained PPF viscosity value, $\eta$, is estimated to be close to $10^{6}$ Pa.s.

At this stage, it can be concluded that increasing the substrate temperature from 10 to $45^{\circ} \mathrm{C}$ dramatically affects the mechanical properties of the PPF, switching from a highly viscous liquid to an elastic solid. Regarding this evolution, a parallel can be drawn with conventional materials by considering the fluid-glass transition. ${ }^{53}$ Considering a polymeric network, at the glass transition temperature, the amorphous regions experience transition from rigid to a more flexible state (rubbery or viscous state).$^{54}$ For plasma polymers, it should be noted that there is no consensus about the occurrence of a glass transition. Only a few studies deal with this aspect. ${ }^{55,56}$ To shed additional light to the mechanical properties of PPF, experiments have been here carried out to 
describe the evolution of the glass transition temperature with $T_{s}$. Although measuring the $T_{g}$ of thin films is still highly challenging, Poleunis et al have recently developed a method based on the temperature dependence of $\mathrm{Ar}_{n}{ }^{+}$cluster backscattering from polymer surfaces during ToF-SIMS experiments. ${ }^{42}$ Briefly, they noticed that, upon bombardment of polymer coatings with $\mathrm{Ar}_{3000}{ }^{+}$ clusters, the intensity ratio of backscattered ions $\mathrm{Ar}_{2}{ }^{+} /\left(\mathrm{Ar}_{2}{ }^{+}+\mathrm{Ar}_{3}{ }^{+}\right)$dramatically changed around a temperature close to the $T_{g}$ of bulk polymers measured by DSC. Since the cluster impacts only probe the topmost nanometers of the surface, where chain mobility might be different from the bulk, this was labelled $\mathrm{T}_{\mathrm{T}}$ for surface transition temperature. The same method has therefore been applied on our PPF and the $\mathrm{Ar}_{2}{ }^{+} /\left(\mathrm{Ar}_{2}{ }^{+}+\mathrm{Ar}_{3}{ }^{+}\right)$ratio has been measured considering a temperature range from $-115^{\circ} \mathrm{C}$ to $110^{\circ} \mathrm{C}$.
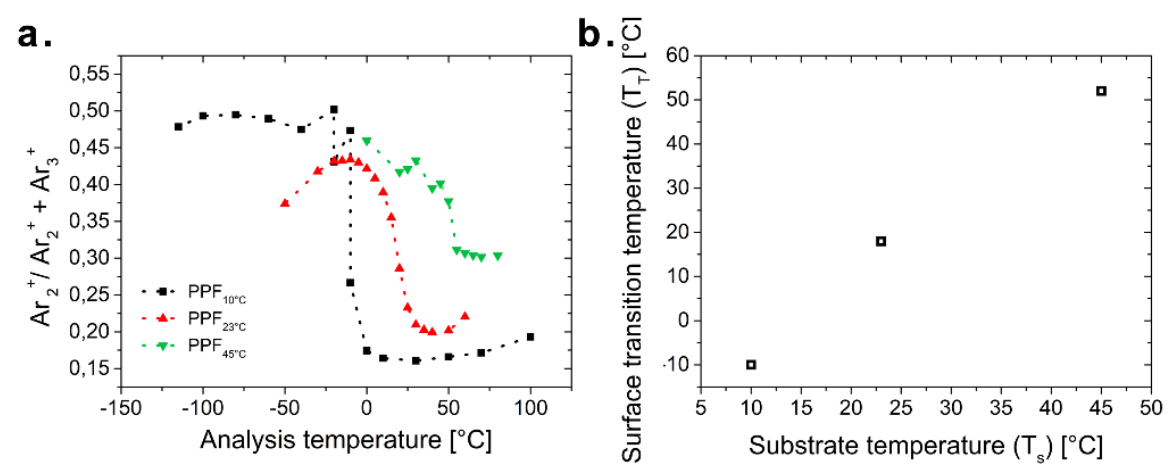

Figure 5: (a) $\mathrm{Ar}_{2}^{+} /\left(\mathrm{Ar}_{2}{ }^{+}+\mathrm{Ar}_{3}{ }^{+}\right)$ratio of backscattered ions collected during ToF-SIMS experiments

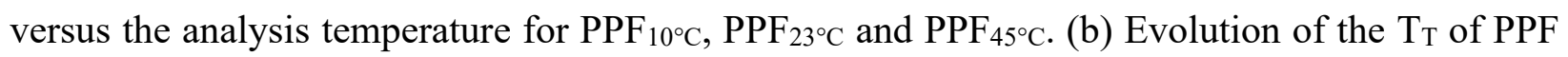
evaluated by ToF-SIMS as function of $\mathrm{T}_{\mathrm{s}}$.

As shown in Figure 5 a, the recorded curves exhibit a sigmoid shape for all samples in agreement with the literature. ${ }^{42}$ From the inflection points of the curves the $\mathrm{T}_{\mathrm{T}}$ is determined and plotted as a function of $\mathrm{T}_{\mathrm{S}}$ (Figure $5 \mathrm{~b}$ ). The $\mathrm{T}_{\mathrm{T}}$ of $\mathrm{PPF}_{10^{\circ} \mathrm{C}}\left(\right.$ i.e. $-10^{\circ} \mathrm{C}$ ) is about $30^{\circ} \mathrm{C}$ lower than the room temperature. For $\mathrm{PPF}_{23^{\circ}} \mathrm{C}$, the $\mathrm{T}_{\mathrm{T}}$ (i.e. $18^{\circ} \mathrm{C}$ ) is close to the room temperature while for $\mathrm{PPF}_{45^{\circ} \mathrm{C}}, \mathrm{T}_{\mathrm{T}}$ 
(i.e. $52^{\circ} \mathrm{C}$ ) is $30^{\circ} \mathrm{C}$ higher. These results are in line with the previously discussed AFM measurements that have been carried out at room temperature $\left(\mathrm{T}_{\text {room }}\right)$ (Table 1). Indeed, for $\mathrm{T}_{\mathrm{T}}<<$ $T_{\text {room, }}$ the PPF behaves as a viscous liquid characterized by a high viscosity value. With $T_{T} \gg>$ $\mathrm{T}_{\text {room, }}$ PPF behaves as an elastic solid characterized by a relatively high rigidity modulus and for $\mathrm{T}_{\mathrm{T}} \sim \mathrm{T}_{\text {room, }}$, the PFF exhibits an intermediate behavior (i.e. viscoelastic).

\begin{tabular}{|l|l|l|l|l|l|l|}
\hline $\mathrm{T}_{\mathrm{s}}\left[{ }^{\circ} \mathrm{C}\right]$ & $\mathrm{E}[\mathrm{GPa}]$ & $\mathrm{E}^{\prime}[\mathrm{GPa}]$ & $\mathrm{E}^{\prime}[\mathrm{GPa}]$ & $\operatorname{Tan} \delta$ & $\eta[\mathrm{Pa} . \mathrm{s}]$ & $\mathrm{T}_{\mathrm{T}}\left[{ }^{\circ} \mathrm{C}\right]$ \\
\hline 10 & $/$ & $/$ & $/$ & $/$ & $10^{6}$ & -10 \\
\hline 23 & $5.10 \pm 0.49$ & $1.61 \pm 0.28$ & $1.17 \pm 0.22$ & $0.72 \pm 0.12$ & $/$ & 18 \\
\hline 45 & $9.94 \pm 5.88$ & $8.51 \pm 3.54$ & $1.95 \pm 1.11$ & $0.24 \pm 0.09$ & $/$ & 52 \\
\hline $10^{*}$ & $1.65 \pm 0.56$ & $0.70 \pm 0.52$ & $0.09 \pm 0.08$ & $0.13 \pm 0.11$ & $/$ & 32 \\
\hline
\end{tabular}

Table 1: Mechanical parameters and surface transition temperature for $\mathrm{PPF}_{10^{\circ}} \mathrm{C}, \mathrm{PPF}_{23^{\circ}} \mathrm{C}$ and

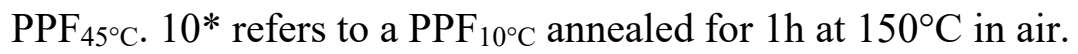

It has been shown for conventional polymers that the glass transition temperature is influenced by the mobility of chain segments altered in turn by the chemical composition and the cross-linking density of the polymeric network. ${ }^{57,58}$ Therefore, in order to gain more understanding on the influence of $\mathrm{T}_{\mathrm{S}}$ on the observed evolution of the glass transition of our PPF, their chemical composition has been evaluated by XPS. 

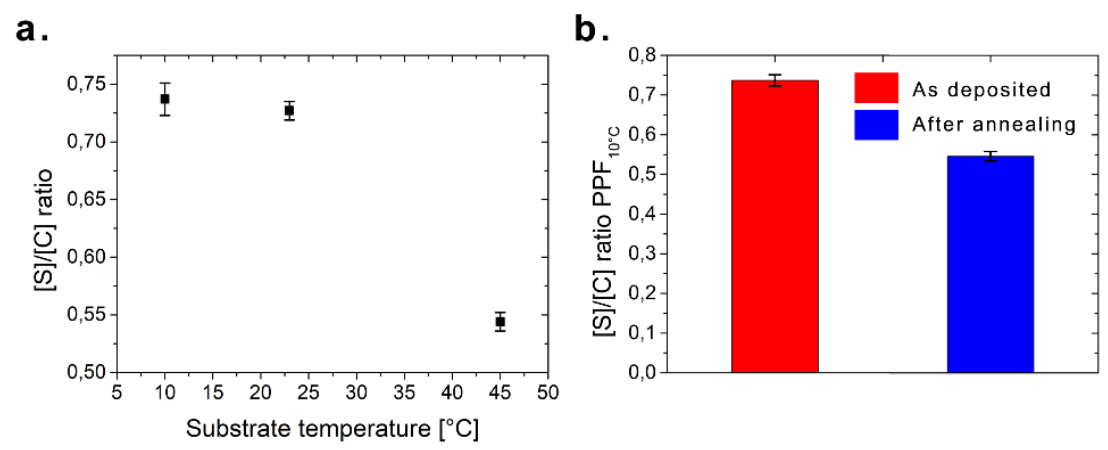

Figure 6: (a) Evolution of the $\mathrm{S} / \mathrm{C}$ ratio as a function of $\mathrm{T}_{\mathrm{s}}$. (b) Evolution of the $\mathrm{S} / \mathrm{C}$ ratio for the as-deposited $\mathrm{PPF}_{10}{ }^{\circ} \mathrm{C}$ and after annealing in air at $150^{\circ} \mathrm{C}$ during $1 \mathrm{~h}$.

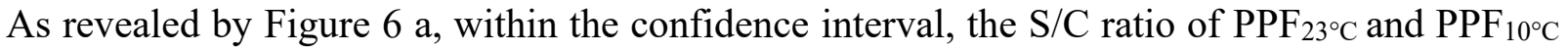
are similar (i.e. $\sim 0.73$ ) and is much lower for $\mathrm{PPF}_{45^{\circ} \mathrm{C}}($ i.e. $\sim 0.55)$. In each case, the $\mathrm{S} / \mathrm{C}$ ratio of PPF is higher than the one of the propanethiol precursor (i.e. 0.33). This observation is rather unusual compared to the value found in the literature for other PPF families with a different heteroelement but in agreement with our previous studies about sulfur-based PPF. ${ }^{29,59,60}$ This behavior is explained by the presence of trapped $\mathrm{H}_{2} \mathrm{~S}$ species within the polymeric network during the PPF growth. Indeed, it has been reported that a large amount of $\mathrm{H}_{2} \mathrm{~S}$ molecules which can be physisorbed at the plasma growing films interface is produced in the plasma. ${ }^{35}$ Decreasing $\mathrm{T}_{\mathrm{s}}$ exponentially prolongs their residence time on the nascent film and therefore increases their probability of being trapped by the condensing material, thus explaining the trend observed in Figure 6 a. $^{61}$

Interestingly, considering the $\mathrm{T}_{\mathrm{g}}$ concept, it is well known for conventional polymers that the presence of small compounds in the polymeric matrix (referred as plasticizers) can modify the $\mathrm{T}_{\mathrm{g}}$ value of the material. ${ }^{58}$ The higher is the concentration of these plasticizers, the lower is the $\mathrm{T}_{\mathrm{g}}$. Considering our data, this could at least partly explain the observed increase of $\mathrm{T}_{\mathrm{T}}$ with $\mathrm{T}_{\mathrm{s}}$. To validate this understanding, the $\mathrm{PPF}_{10^{\circ} \mathrm{C}}$ has been annealed for $1 \mathrm{~h}$ at $150^{\circ} \mathrm{C}$ in air in order to 
thermally activate the outward diffusion of the trapped $\mathrm{H}_{2} \mathrm{~S}$ from the PPF matrix. As a consequence, the $\mathrm{S} / \mathrm{C}$ ratio is reduced from $0.74 \pm 0.01$ to $0.55 \pm 0.01$ (Figure $6 \mathrm{~b}$ ), in line with previously reported data ${ }^{62}$ accompanied by a decrease in the thickness of $\sim 70 \%$. This results in an increase of $\mathrm{T}_{\mathrm{T}}$ from $-10^{\circ} \mathrm{C}$ to $32^{\circ} \mathrm{C}$, obviously also affecting the mechanical behavior of the material (Figure $\mathrm{S} 2$ ). Indeed, since $\mathrm{T}_{\mathrm{T}}$ is now $>\mathrm{T}_{\text {room, }}$ the shape of the force-distance curves extracted from the AFM Peak-Force QNM analysis on this material evolves dramatically compared to the as-deposited PPF (Figure S3). The JKR theory can now be applied on these curves revealing a rigidity modulus of $1.65 \pm 0.56 \mathrm{GPa}$. In addition, by nDMA measurements, a storage modulus of $0.70 \pm 0.52 \mathrm{GPa}$, a loss modulus of $0.09 \pm 0.08 \mathrm{GPa}$ and a Tan Delta of $0.13+/-0.11$ have been measured (Figure 2). From these data, it can be concluded that the annealing of the asdeposited $\mathrm{PPF}_{10^{\circ} \mathrm{C}}$ film significantly alters its chemical composition and its viscoelastic properties. Although these data could indicate that the proportion of trapped species directly affects the $\mathrm{T}_{\mathrm{T}}$ and hence the viscoelastic properties, this cannot completely explain the difference of $\mathrm{T}_{\mathrm{T}}$ between the as-deposited PPF. Indeed, after the annealing, the $\mathrm{PPF}_{10^{\circ} \mathrm{C}}$ exhibits a similar $\mathrm{S} / \mathrm{C}$ ratio than $\mathrm{PPF}_{45^{\circ} \mathrm{C}}$ (i.e. 0.55) but lower $\mathrm{T}_{\mathrm{T}}$ and rigidity, storage and loss moduli (Table 1). This statement is

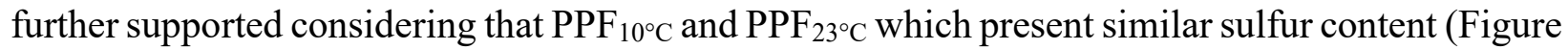
6 a) are significantly different in terms of mechanical properties (i.e. high viscous liquid vs viscoelastic solid) and $\mathrm{T}_{\mathrm{T}}$ (i.e. $-10^{\circ} \mathrm{C}$ vs $18^{\circ} \mathrm{C}$ respectively).

The other conventionally reported reason for the observed evolution is the variation of the crosslinking density of the materials. ${ }^{63}$ Based on these considerations, it can be proposed in our case that when $\mathrm{T}_{\mathrm{s}}$ shifts from 10 to $23^{\circ} \mathrm{C}$, a critical value of the PPF cross-linking degree is reached, inducing a transition from a liquid to a viscoelastic solid, reducing the mobility of the molecular segments and thus, increasing the $\mathrm{T}_{\mathrm{T}}$. Further increasing $\mathrm{T}_{\mathrm{s}}$ until $45^{\circ} \mathrm{C}$ would give rise to an even 
more cross-linked film with a lower proportion of trapped sulfur-based species; both aspects likely contributing to increase $\mathrm{T}_{\mathrm{T}}$ and the stiffness of the polymeric material.

This hypothesis has been studied by additional ToF-SIMS measurements to compare the crosslinking degree of our as-deposited PPF. Indeed, it has been demonstrated that the cross-linking density of PPF is inversely correlated to the total amount of secondary ions collected $\left(\sum \mathrm{sI}\right)$ for ToF-SIMS spectra recorded in positive mode. ${ }^{64}$ Figure 7 a reveals that $\sum$ sI decreases with $\mathrm{T}_{\mathrm{s}}$ which suggests that the cross-linking density of our PPF increases.
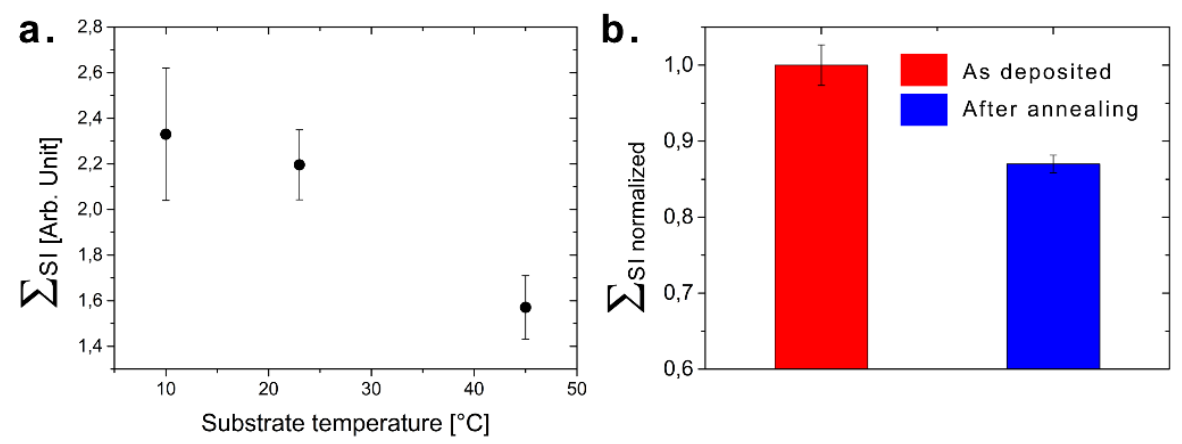

Figure 7: (a) Evolution of $\sum \mathrm{sI}$ as a function of $\mathrm{T}_{\mathrm{s}}$. (b) Evolution of $\sum \mathrm{sI}$ for the as-deposited $\mathrm{PPF}_{10^{\circ} \mathrm{C}}$ and after annealing in air at $150^{\circ} \mathrm{C}$ during $1 \mathrm{~h}$.

Such an evolution is in line with previously reported data and is explained by a decrease of the associated energy load by depositing atoms. ${ }^{61}$

In order to complete this study, the impact of the annealing of $\mathrm{PPF}_{10^{\circ} \mathrm{C}}$ on the cross-linking degree has also been investigated. Figure $7 \mathrm{~b}$ reveals that the annealing induces an increase in the crosslinking density of the PPF that might be explained considering the well-reported presence of free radicals in the as-deposited PPF. ${ }^{65}$ And yet, radical reactions between adjacent polymer segments inducing additional cross-links is likely to take place and be improved by the annealing procedure. ${ }^{59}$ In addition, the release of the $\mathrm{H}_{2} \mathrm{~S}$ trapped species from the matrix during the annealing procedure likely facilitates the reactions between molecular segments. This phenomenon 
therefore contributes as well to the increase in $\mathrm{T}_{\mathrm{T}}$ that is observed for $\mathrm{PPF}_{10^{\circ} \mathrm{C}}$ after annealing. Altogether, these data therefore confirms that the evolution of the crosslinking degree should also be considered to explain our results in term of $\mathrm{T}_{\mathrm{T}}$ and mechanical properties.

Finally, to illustrate the interest to tune on demand the surface transtion temperature and then in turn the mechanical behavior of the polymeric materials, bilayer systems constituted by a bottom PPF and a top Al layer have been synthesized based on a methodology described elsewhere. ${ }^{34}$ It has been demonstrated that depending on the physicochemical properties of the PPF, nanowrinkled surfaces can be obtained of interest for the fabrication of flexible electrodes. ${ }^{34}$

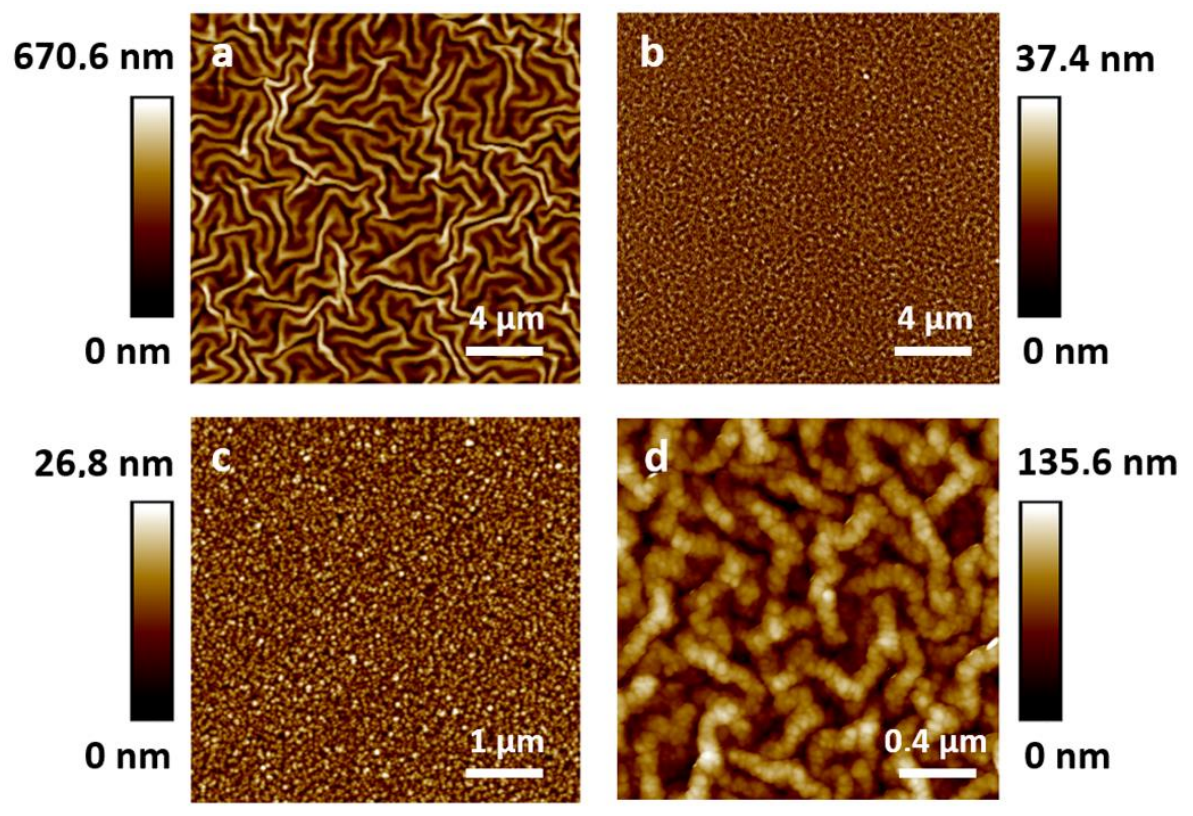

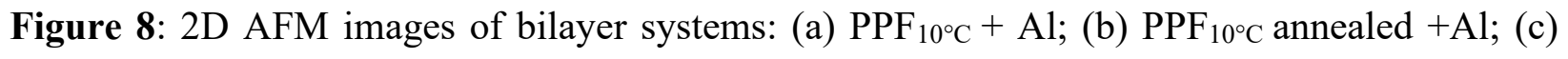
$\mathrm{PPF}_{45^{\circ}} \mathrm{C}+\mathrm{Al} ;(\mathrm{d})\left(\mathrm{PPF}_{45^{\circ}} \mathrm{C}\right) \mathrm{T}=100^{\circ} \mathrm{C}+\mathrm{Al}$.

In a first attempt, an $\mathrm{Al}$ layer has been deposited on a $\mathrm{PPF}_{10^{\circ} \mathrm{C}}$ directly after its synthesis. As it can be observed in Figure 8 a, wrinkles spontaneously appeared at the surface of the material with a wavelength (i.e. peak-to-peak horizontal distance, $\lambda$ ) of $475.2 \pm 48.5 \mathrm{~nm}$ and an amplitude (i.e. peak-to-valley vertical distance, A) of $331.4 \pm 40.5 \mathrm{~nm}$ in line with our previous study. ${ }^{34}$ On the 
other hand, if the $\mathrm{Al}$ coating is deposited on the top $\mathrm{PPF}_{10^{\circ} \mathrm{C}}$ after having experienced a thermal treatment (i.e. $1 \mathrm{~h}$ at $150^{\circ} \mathrm{C}$ in air), the formation of wrinkles is hindered (Figure $8 \mathrm{~b}$ ). This behavior is explained by the increase in $\mathrm{T}_{\mathrm{T}}$ for the annealed sample which then behaves like an elastic solid with a rigidity modulus of $1.83 \pm 0.98 \mathrm{GPa}$. For this value, the critical strain for wrinkling related to the stiffness of the PPF becomes too high to enable the surface reorganization. ${ }^{34}$

Similarly, if an Al layer is deposited on $\mathrm{PPF}_{45^{\circ} \mathrm{C}}$ directly after its synthesis, no wrinkling phenomenon appears; the rigidity modulus being too high (i.e. $9.94 \pm 5.88 \mathrm{GPa}$ ) for a surface reorganization to occur (Figure $8 \mathrm{c}$ ). On the other hand, if the deposition of the $\mathrm{Al}$ coating is

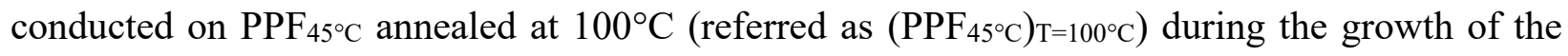
metallic layer, nano-wrinkles appear with $\lambda$ and $A$ of $152.6 \pm 18.9 \mathrm{~nm}$ and $58.18 \pm 10.15 \mathrm{~nm}$, respectively (Figure $8 \mathrm{~d}$ ). Actually, annealing the $\mathrm{PPF}$ above its $\mathrm{T}_{\mathrm{T}}\left(\right.$ i.e. $100^{\circ} \mathrm{C}$ vs $52^{\circ} \mathrm{C}$ ) induces a transition from a hard elastic solid to a softer material with a reduced rigidity modulus, deformable enough to wrap and form wrinkles. This set of experiments clearly highlights the importance of knowing $\mathrm{T}_{\mathrm{T}}$ of PPF for controlling and predicting their mechanical response when involved in a bilayer system and in turn their morphological reorganization. 


\section{Conclusions}

In this work, the influence of the substrate temperature on the mechanical properties of propanethiol plasma polymer films was investigated. As a general trend, the stiffness of the PPF increases with the substrate temperature. Interestingly, the thermal conditions of the substrate strongly impact the mechanical nature of the PPF: from a high viscous thin film (with a viscosity about $10^{6}$ Pa.s) to an hard elastic solid (with a rigidity modulus of $\sim 10 \mathrm{GPa}$ ) when the substrate temperature evolves from 10 to $45^{\circ} \mathrm{C}$.

The evolution of the PPF mechanical properties is correlated with the variation of their surface transition temperature related to the glass transition evaluated by ToF-SIMS showing that the $\mathrm{T}_{\mathrm{T}}$ (from $-10^{\circ} \mathrm{C}$ to $52^{\circ} \mathrm{C}$ ) increases with $\mathrm{T}_{\mathrm{s}}$. This behavior is ascribed to the alteration of the chemical composition and the cross-linking degree of PPF with the substrate temperature during their growth. Indeed, it has been shown that $\mathrm{T}_{\mathrm{s}}$ controls the proportion of trapped sulfur-based species in the PPF matrix acting as plasticizers and then decreasing $\mathrm{T}_{\mathrm{T}}$. Furthermore, increasing $\mathrm{T}_{\mathrm{s}}$ gives rise to more cross-linked PPF limiting the chain mobility and thus resulting in higher $\mathrm{T}_{\mathrm{T}}$.

Although generally not considered in the field of plasma polymerization, the whole set of our results unambiguously highlights the importance of the glass transition for understanding the viscoelastic properties of PPF, clearly opening new research directions in the field as for instance the development of mechanically responsive PPF. As a matter of fact, it has been shown that the availability to tune $\mathrm{T}_{\mathrm{T}}$ with the thermal conditions of the substrate allows controlling the mechanical deformation of PPF when involved in a bilayer system of interest for the fabrication of nanopattern appealing for numerous research domains including stretchable solar cells, bioinspired devices, and so forth. 


\section{Conflicts of interest}

There are no conflicts to declare.

\section{$\underline{\text { Acknowledgement }}$}

D.T thanks the "Région Wallonne" through the CLEANAIR project for its financial support. 


\section{References}

1. P. P. Deshpande, N. G. Jadhav, V. J. Gelling and D. Sazou, Journal of Coatings Technology and Research, 2014, 11, 473-494.

2. R.-G. Hu, S. Zhang, J.-F. Bu, C.-J. Lin and G.-L. Song, Progress in Organic Coatings, 2012, 73, 129-141.

3. S. Krishnan, R. J. Ward, A. Hexemer, K. E. Sohn, K. L. Lee, E. R. Angert, D. A. Fischer, E. J. Kramer and C. K. Ober, Langmuir, 2006, 22, 11255-11266.

4. K. Vacheethasanee and R. E. Marchant, Journal of Biomedical Materials Research: An Official Journal of The Society for Biomaterials, The Japanese Society for Biomaterials, and The Australian Society for Biomaterials and the Korean Society for Biomaterials, 2000, 50, 302-312.

5. B. Kong, J. S. Choi, S. Jeon and I. S. Choi, Biomaterials, 2009, 30, 5514-5522.

6. B. Lee, A. Jiao, S. Yu, J. B. You, D.-H. Kim and S. G. Im, Acta biomaterialia, 2013, 9, 7691-7698.

7. F. M. Li, Y. Vygranenko, S. Koul and A. Nathan, Journal of Vacuum Science \& Technology A: Vacuum, Surfaces, and Films, 2006, 24, 657-662.

8. J. Jang, J. Ha and K. Kim, Thin Solid Films, 2008, 516, 3152-3156.

9. P. Vanlaeke, G. Vanhoyland, T. Aernouts, D. Cheyns, C. Deibel, J. Manca, P. Heremans and J. Poortmans, Thin solid films, 2006, 511, 358-361.

10. M. S. Zoromba, M. Abdel-Aziz, M. Bassyouni, H. Bahaitham and A. Al-Hossainy, Journal of Solid State Electrochemistry, 2018, 22, 3673-3687.

11. M. Li, J. Liang, X. Wang and M. Zhang, Sensors, 2020, 20, 371.

12. N. D. Leipzig and M. S. Shoichet, Biomaterials, 2009, 30, 6867-6878.

13. L. J. Guo, Advanced materials, 2007, 19, 495-513.

14. J. Yin, J. L. Yagüe, D. Eggenspieler, K. K. Gleason and M. C. Boyce, Advanced materials, 2012, 24, 5441-5446.

15. J. L. Yagüe, J. Yin, M. C. Boyce and K. K. Gleason, Physics Procedia, 2013, 46, 40-45.

16. D. Y. Khang, J. A. Rogers and H. H. Lee, Advanced Functional Materials, 2009, 19, 15261536.

17. C. S. Ware, T. Smith-Palmer, S. Peppou-Chapman, L. R. Scarratt, E. M. Humphries, D. Balzer and C. Neto, ACS applied materials \& interfaces, 2018, 10, 4173-4182.

18. F. Greco, L. Ventrelli, P. Dario, B. Mazzolai and V. Mattoli, Int. J. Hydrogen Energy, 2012, 37, 17529-17539.

19. N. K. L. Wiziack, L. G. Paterno, F. J. Fonseca and L. H. C. Mattoso, Sensors and Actuators B: Chemical, 2007, 122, 484-492.

20. D. Correa, E. Medeiros, J. Oliveira, L. Paterno and L. H. Mattoso, Journal of nanoscience and nanotechnology, 2014, 14, 6509-6527.

21. H. Wan, J. Shen, N. Gao, J. Liu, Y. Gao and L. Zhang, Soft matter, 2018, 14, 2379-2390.

22. S. Xue, Y. Wu, M. Guo, Y. Xia, D. Liu, H. Zhou and W. Lei, Soft Matter, 2019, 15, 36803688 .

23. D. Thiry, S. Konstantinidis, J. Cornil and R. Snyders, Thin Solid Films, 2016, 606, 19-44.

24. D. Thiry, F. Reniers and R. Snyders, Surface Modification of Polymers: Methods and Applications, 2019, 67-106. 
25. H. Biederman, Plasma polymer films, World Scientific, 2004.

26. N. Inagaki, Plasma surface modification and plasma polymerization, CRC Press, 1996.

27. P. Cools, H. Declercq, N. De Geyter and R. Morent, Applied Surface Science, 2018, 432, 214-223.

28. D. Hegemann, I. Indutnyi, L. Zajičková, E. Makhneva, Z. Farka, Y. Ushenin and M. Vandenbossche, Plasma Processes and Polymers, 2018, 15, 1800090.

29. C. Vandenabeele, M. Buddhadasa, P.-L. Girard-Lauriault and R. Snyders, Thin Solid Films, 2017, 630, 100-107.

30. E. Kasparek, D. Thiry, J. R. Tavares, M. R. Wertheimer, R. Snyders and P. L. GirardLauriault, Plasma Processes and Polymers, 2018, 15, 1800036.

31. A. Michelmore, D. A. Steele, D. E. Robinson, J. D. Whittle and R. D. Short, Soft Matter, 2013, 9, 6167-6175.

32. S. Ligot, E. Bousser, D. Cossement, J. Klemberg-Sapieha, P. Viville, P. Dubois and R. Snyders, Plasma Process. Polym., 2015, 12, 508-518.

33. J. C. de Oliveira, A. Airoudj, P. Kunemann, F. Bally-Le Gall and V. Roucoules, SN Applied Sciences, 2021, 3, 1-15.

34. D. Thiry, N. Vinx, P. Damman, F. J. Aparicio, P. Y. Tessier, D. Moerman, P. Leclère, T. Godfroid, S. Desprez and R. Snyders, Plasma Process. Polym., 2020, 17, 2000119.

35. D. Thiry, N. Britun, S. Konstantinidis, J.-P. Dauchot, M. Guillaume, J. Cornil and R. Snyders, The Journal of Physical Chemistry C, 2013, 117, 9843-9851.

36. M. Veuillet, L. Ploux, A. Airoudj, Y. Gourbeyre, E. Gaudichet-Maurin and V. Roucoules, Plasma Processes and Polymers, 2017, 14.

37. B. Pittenger, S. Osechinskiy, D. Yablon and T. Mueller, JOM, 2019, 71, 3390-3398.

38. P. Trtik, J. Kaufmann and U. Volz, Cement and concrete research, 2012, 42, 215-221.

39. K. L. Johnson, K. Kendall and a. Roberts, Proceedings of the royal society of London. A. mathematical and physical sciences, 1971, 324, 301-313.

40. J. E. Sader, I. Larson, P. Mulvaney and L. R. White, Review of Scientific Instruments, 1995, 66, 3789-3798.

41. D. Wang, S. Fujinami, K. Nakajima, S. Inukai, H. Ueki, A. Magario, T. Noguchi, M. Endo and T. Nishi, Polymer, 2010, 51, 2455-2459.

42. C. Poleunis, V. Cristaudo and A. Delcorte, J. Am. Soc. Mass. Spectrom., 2017, 29, 4-7.

43. A. Delcorte, V. Delmez, C. C. Dupont-Gillain, C. Lauzin, H. Jefford, M. Chundak, C. Poleunis and K. Moshkunov, Physical Chemistry Chemical Physics, 2020.

44. M. Chundak, C. Poleunis, V. Delmez, H. Jefford, L. Bonnaud, A. M. Jonas and A. Delcorte, Applied Surface Science, 2020, 533, 147473.

45. K. Geng and O. K. Tsui, Macromolecules, 2016, 49, 2671-2678.

46. K. P. Menard and N. Menard, Dynamic mechanical analysis, CRC press, 2020.

47. Z. Elkaakour, J. Aime, T. Bouhacina, C. Odin and T. Masuda, Physical review letters, 1994, 73, 3231.

48. S. Kassavetis, K. Mitsakakis and S. Logothetidis, Materials Science and Engineering: $C$, 2007, 27, 1456-1460.

49. T. Salez, J. D. McGraw, S. L. Cormier, O. Bäumchen, K. Dalnoki-Veress and E. Raphäl, The European Physical Journal E, 2012, 35, 1-9.

50. A. Cameron and C. Mc Ettles, 1981.

51. T. Papanastasiou, G. Georgiou and A. N. Alexandrou, Viscous fluid flow, CRC press, 1999. 
52. S. Coulson, I. Woodward, J. Badyal, S. Brewer and C. Willis, Chemistry of materials, 2000, 12, 2031-2038.

53. G. Biroli and J. P. Garrahan, The Journal of chemical physics, 2013, 138, 12 A301.

54. A. Shrivastava, Introduction to plastics engineering, William Andrew, 2018.

55. S. Yakut, H. K. Ulutas, I. Melnichuk, A. Choukourov, H. Biederman and D. Deger, Thin Solid Films, 2016, 616, 279-286.

56. P. Pleskunov, D. Nikitin, R. Tafiichuk, A. Shelemin, J. Hanuš, J. Kousal, Z. k. Krtouš, I. Khalakhan, P. Kúš and T. Nasu, The Journal of Physical Chemistry B, 2020, 124, 668-678.

57. B. S. Chiou and P. E. Schoen, Journal of applied polymer science, 2002, 83, 212-223.

58. V. R. Gowariker, N. Viswanathan and J. Sreedhar, Polymer science, New Age International, 1986.

59. K. Vasilev, L. Britcher, A. Casanal and H. J. Griesser, J. Phys. Chem. B, 2008, 112, 1091510921.

60. D. Thiry, F. J. Aparicio, N. Britun and R. Snyders, Surface and Coatings Technology, 2014, 241, 2-7.

61. F. J. Aparicio, D. Thiry, P. Laha and R. Snyders, Plasma Process. Polym., 2016, 13, 814822.

62. D. Thiry, N. Vinx, F. J. Aparicio, D. Moerman, R. Lazzaroni, D. Cossement and R. Snyders, Thin Solid Films, 2019, 672, 26-32.

63. H. H. Winter and F. Chambon, Journal of rheology, 1986, 30, 367-382.

64. U. Oran, S. Swaraj, J. F. Friedrich and W. E. Unger, Plasma Process. Polym., 2004, 1, $141-$ 152.

65. S. Ershov, F. Khelifa, P. Dubois and R. Snyders, ACS applied materials \& interfaces, 2013, 5, 4216-4223. 